\title{
Genetic fine-mapping of DIPLOSPOROUS in Taraxacum (dandelion; Asteraceae) indicates a duplicated DIP-gene
}

\author{
Kitty Vijverberg ${ }^{1,2^{*}}$, Slavica Milanovic-Ivanovic ${ }^{1}$, Tanja Bakx-Schotman ${ }^{1}$, Peter J van Dijk ${ }^{1,3}$
}

\begin{abstract}
Background: DIPLOSPOROUS (DIP) is the locus for diplospory in Taraxacum, associated to unreduced female gamete formation in apomicts. Apomicts reproduce clonally through seeds, including apomeiosis, parthenogenesis, and autonomous or pseudogamous endosperm formation. In Taraxacum, diplospory results in first division restitution (FDR) nuclei, and inherits as a dominant, monogenic trait, independent from the other apomixis elements. A preliminary genetic linkage map indicated that the DIP-locus lacks suppression of recombination, which is unique among all other map-based cloning efforts of apomeiosis to date. FDR as well as apomixis as a whole are of interest in plant breeding, allowing for polyploidization and fixation of hybrid vigor, respectively. No dominant FDR or apomixis genes have yet been isolated. Here, we zoom-in to the DIP-locus by largely extending our initial mapping population, and by analyzing (local) suppression of recombination and allele sequence divergence (ASD).

Results: We identified 24 recombinants between two most closely linked molecular markers to DIP in an F1population of 2227 plants that segregates for diplospory and lacks parthenogenesis. Both markers segregated c. 1:1 in the entire population, indicating a 1:1 segregation rate of diplospory. Fine-mapping showed three amplified fragment length polymorphisms (AFLPs) closest to DIP at $0.2 \mathrm{cM}$ at one flank and a single AFLP at $0.4 \mathrm{CM}$ at the other flank. Our data lacked strong evidence for ASD at marker regions close to DIP. An unexpected bias towards diplosporous plants among the recombinants (20 out of 24) was found. One third of these diplosporous recombinants showed incomplete penetrance of 50-85\% diplospory.

Conclusions: Our data give interesting new insights into the structure of the diplospory locus in Taraxacum. We postulate a locus with a minimum of two DIP-genes and possibly including one or two enhancers or cis-regulatory elements on the basis of the bias towards diplosporous recombinants and incomplete penetrance of diplospory in some of them. We define the DIP-locus to $0.6 \mathrm{cM}$, which is estimated to cover $\sim 200-300 \mathrm{~Kb}$, with the closest marker at $0.2 \mathrm{cM}$. Our results confirm the minor role of suppression of recombination and ASD around DIP, making it an excellent candidate to isolate via a chromosome-walking approach.
\end{abstract}

\section{Background}

Most seed plants reproduce sexually, but a proportion of c. $0.1 \%$ reproduce asexually through seeds, a process also known as apomixis, sensu stricto, or agamospermy $[1,2]$. In apomictic plants, the embryo sac arises from an unreduced gametophytic cell (diplospory) or a sporophytic cell of the ovule (apospory), followed by further gametogenesis. At maturity, the embryo develops parthenogenetically (without fertilization) from the egg

\footnotetext{
* Correspondence: k.vijverberg@science.ru.nl

${ }^{1}$ Netherlands Institute of Ecology (NIOO-KNAW), Centre for Terrestrial Ecology, NL 6666GA Heteren, The Netherlands
}

cell, and the endosperm develops pseudogamously (requiring fertilization) or, in a minority of apomictic species, autonomously, from the central cell [reviewed by [3]]. Diplosporous apomixis can be mitotic, that is, without meiosis at all, or meiotic, in which meiosis is entered but results in nuclear restitution $[4,5]$, also known as first division restitution (FDR [6]). Apart from possible mutations, apomictic offspring are genetically identical to the mother plant. Apomixis is restricted to the female reproductive pathway, giving the opportunity to investigate its genetics in hermaphroditic apomicts by using them as pollen donors. With the exception of

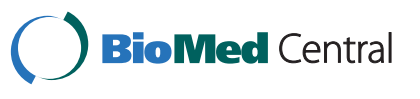

C 2010 Vijverberg et al; licensee BioMed Central Ltd. This is an Open Access article distributed under the terms of the Creative Commons Attribution License (http://creativecommons.org/licenses/by/2.0), which permits unrestricted use, distribution, and reproduction in any medium, provided the original work is properly cited. 
Allium and some (sub)tropical fruit trees and forage grasses, natural apomixis is absent from crop species.

Apomixis is of interest in plant breeding and seed production, because it allows for the fixation and unlimited propagation of complex and heterozygous genotypes [7]. Engineering apomixis into crop plants could promise social and economic benefits that would challenge those of the Green Revolution [8]. Advantages of apomictic reproduction also include the rapid generation of superior forms from novel germplasm, the avoidance of complications associated with sexual reproduction, e.g., self-incompatibility, and the prevention of horizontal disease transfer $[2,9]$. Separate elements of apomixis can be of interest in plant breeding in various ways, such as for raising the ploidy levels by using diplospory or apospory, forming maternal dihaploids by using parthenogenesis, and alternating ploidy levels between generations by applying these elements alternatively [10]. In a more fundamental sense, apomixes is of interest in the context of the paradox of sex, questioning why sexual reproducing organisms are so successful in nature despite advantages of asexual reproduction [11-13]. For all of these interests, the genetics and molecular basis of apomixis have been investigated intensively during last decades [reviewed by $[2,14]]$. Despite these efforts, the understanding of the molecular basis of apomictic reproduction and its use as a tool in plant breeding are still at their beginning.

Efforts to understand the molecular basis of apomixis and to introduce it into crop species include the introgression via classical breeding approaches with apomictic relatives [reviewed by [15]], the unraveling of its genetic control in natural apomicts followed by attempts to map-based clone the genes associated [reviewed by [16]], and the identification of genes that control elements of apomixis in well-defined sexual species [reviewed by [17]]. Up to now, stable introgression of apomixis into crops via breeding, together with an accompanying preservation of seed yield, has failed. The isolation of apomixis genes from natural apomicts appeared also be difficult, because in most species these genes are associated with large genomic regions in which recombination is suppressed. Despite this difficulty, evidence increases for the multigenic control of apomixis, particularly the separate control of apomeiosis and parthenogenesis $[16,18,19]$, and genes associated with apospory have been reported, including $B A B Y$ BOOM-like genes in Pennisetum [20] and HAPPY in Hypericum [19]. Some recent progress has been made with the third approach in the model species Arabidopsis, by identifying the DYAD/SWITCH1 (SWI1) gene [21] and characterizing dyad plants [22], and by identifying the Omission of Second Division 1 (OSD1) gene and creating osd 1/Atspo11-1/Atrec 8 triple mutants (MiMe) [23]. DYAD/SWI1 is a regulator of meiotic chromosome organization and mutation of this gene leads to FDR. OSD1 mutants result in SDR, and in the triple mutant form $M i M e$, to mitotic division. Although dyad is recessive and results in the production of unreduced gametes at low frequencies and $M i M e$ is a triple mutant, these findings are first steps in the possible engineering of apomixis or elements thereof in plant breeding. A third gene that was recently found to be involved in female gamete formation is ARGONAUTE9 (AGO9) [24]. Mutations of this gene lead to developing megagametophytes also from somatic cells, being reminiscent of apospory. Here, we focus on the second approach, using the natural apomict Taraxacum officinale (common dandelion, Asteraceae) in order to map diplospory.

Attempts to map apomeiosis, either diplospory or apospory, have particularly been made in species of the Poaceae (grasses) and Asteraceae [reviewed by $[16,25]$. The general view emerging from the studies in Poaceae is that apomixis inherits as a whole as a dominant, monogenic trait, and that molecular markers cluster with the trait, indicating (strong) suppression of recombination at these loci. This was found for aposporous species of Panicum [26], Paspalum [27,28], Pennisetum and Cenchrus [29-31], and diplosporous Tripsacum dactyloides [32]. Exceptions were found in Brachiaria, that lacked clustering of markers at the locus for aposporous apomixis in an initial mapping population [33], and in Poa, that showed independent inheritance of apospory and parthenogenesis and no marker-clustering at the locus of the latter, whereas apospory was not mapped [34]. In a later study in Poa, a five locus model for the inheritance of apomixis confirmed the independent inheritance of apospory and parthenogenesis [35]. A recent study in Panicum indicated independent inheritance of all three apomixis elements in this species [18]. The general view from studies in Asteraceae is that apomeiosis and parthenogenesis inherit independently and that suppression of recombination is indicated at some but not all loci. In Erigeron annuus, the locus for diplospory showed clustering of markers, whereas the locus for parthenogenesis did not [36]. In Hieracium spp., a deletion mapping study was initiated in order to avoid anticipated difficulties associated with map-based cloning at recombinationally suppressed loci [37]. The results showed independent loci for apospory and parthenogenesis, designated Loss Of Apospory (LOA) and Loss Of Parthenogenesis (LOP), respectively. In Taraxacum, a mapping study showed regular distribution of markers over the DIPLOSPOROUS $(D I P)$-chromosomal region, indicating the occurrence of recombination in this region [38]. Preliminary mapping of PARTHENOGENESIS (PAR) in this species showed co-segregation of markers with the trait, suggesting suppression of recombination at this locus [PJ Van Dijk et al. unpublished results]. Since the DIP-chromosomal 
region in Taraxacum lacks evidence for suppression of recombination, it is one of the best candidates to isolate (a) gene(s) for apomeiosis via a map-based cloning approach.

The suppression of recombination found in most mapping studies of apomixis loci to date indicate (strong) divergence of alleles at these loci. Evidence for this was particularly found in Pennisetum and Paspalum that showed hemizygosity at the loci for aposporous apomixis $[29,28]$. Allele sequence divergence (ASD) can be expected under (long-term) asexual, non-recombining, conditions [39]. Depending on the time of asexuality, the two (or more) alleles of a gene can acquire high levels of heterozygosity and the homologous chromosomes can accumulate different chromosome rearrangements. Experimental evidence for ASD comes from the Bdelloid rotifers, an ancient asexual lineage of freshwater invertebrates, showing greater sequence divergence between formerly alleles of several protein-coding genes in a single individual than between the same loci in related species $[40,41]$. In hermaphroditic apomicts, in which the male sexual pathway allows for recombination, the process of ASD will be retarded, but will, according to computer simulations, still occur [42]. ASD can also be reduced by gene conversion and mitotic crossing-over. In T. officinale, no evidence for suppression of recombination was found at the DIP-locus [38]. At one flank at $\sim 3.5 \mathrm{cM}$ from $D I P$, linkage at $0-1 \mathrm{cM}$ was found between two microsatellite loci (Mst53 and Mst78) that were 5-10 cM apart in sexual relatives [42-44]. This might refer to local suppression of recombination at a region close to DIP and was among our investigations of the study presented here.

T. officinale s.l. consists of polyploid, mostly triploid $(2 n=3 x=24)$ apomicts and diploid $(2 n=2 x=16)$ sexual individuals [45]. Apomictic Taraxacum is diplosporous, with parthenogenetic embryo development and autonomous endosperm formation [46]. Diplospory is of the meiotic type (Taraxacum type [5]) in which bivalent formation during female meiosis I is omitted or occurs at low frequencies [47-50], followed by nuclear restitution and normal meiosis II. Molecular marker studies lacked evidence for genetic exchange during this process, but more extensive studies on genetic consequences of possible recombination events have to be performed. Crossing studies revealed that diplospory and parthenogenesis inherit independently in T. officinale [51], whereas the precise inheritance of autonomous endosperm formation is yet unresolved. Diplospory showed dominant, monogenic inheritance, indicating genotypes $D d d, D d d d$, and $d d$ for tri- and tetraploid apomicts and diploid sexuals, respectively [44]. Parthenogenesis also inherits as a dominant, monogenic trait [[51], PJ Van Dijk et al. unpublished results]. A significant linkage of the rDNA locus to two Mst loci, Mst53 and Mst78, that were linked to diplospory, suggest a physical location of DIP on one of the nucleolar organizer region (NOR) chromosomes [44]. This was in agreement with a cytological observation in a triploid disomic plant $(2 n=3 x=24-1)$ that lacked one of the NOR-chromosomes accompanying with the loss of apomixis [52,44]. Fluorescent in situ hybridization (FISH) experiments with bacterial artificial chromosomes (BACs) linked to DIP also indicated a location of DIP on one of the NOR-chromosomes [RJ Vašut et al. unpublished results]. Apomixis in Taraxacum is mostly obligate, indicating that the dominant DIP allele is fully penetrant. Occasional formation of quite a high number of bivalents followed by meiotic reduction has, however, been reported [49] as were crossing experiments that resulted in some progeny that indicated reduced egg cells from the diplosporous seed parent [53]. These observations may indicate that DIP is not fully penetrant in Taraxacum in all accessions or under all conditions. Since DIP is expressed during female meiosis only, it is transferred via reductional and recombinational male meiosis, thereby allowing us to map the trait.

A first map of DIP was based on 73 plants of a segregating population, 34 amplified fragment length polymorphisms (AFLPs) resolved by a bulked segregant analysis and linked alleles at two Mst loci [38]. Total length of this map was $18.6 \mathrm{cM}$ and markers were found at both sides of DIP, corresponding to 5.9 and $12.7 \mathrm{cM}$, respectively. None of the markers completely co-segregated with DIP, and the closest markers concerned unresolved groups of three AFLPs at $1.4 \mathrm{cM}$ from DIP at each flank. The regular distribution of markers over the $D I P$-chromosomal region indicated that extensive suppression of recombination was lacking at the apomeiosis locus in T. officinale. A number of AFLPs was successfully converted into PCR-based markers in order to facilitate further fine mapping of $D I P$ as well as to compare sequences of marker regions between DIP and non-DIP homolog's [38]. The results included two dominant sequence characterized amplified regions (SCARs) from within the AFLP-groups closest to DIP: S8 and S10, and one co-dominant single nucleotide polymorphism (SNP) at a larger distance from DIP: S4. The other markers showed PCR-products in sexual as well as apomictic individuals, lacking evidence for obvious sequence divergence between the DIP and non$D I P$ homolog's or the presence of hemizygosity at the DIP-chromosomal region in Taraxacum.

As part of our map-based cloning effort of DIP, we here continued the genetic linkage mapping of $D I P$ and the characterization of the DIP-chromosomal region in T. officinale. We extended the segregating population used for initially mapping to a total of 2227 plants. This population included diplospory in the paternal plant, 
but lacked parthenogenesis. Plants were screened for recombination between the PCR-markers S8 and S10, and recombinants were phenotyped for their mode of reproduction and analyzed for AFLPs known to be closely linked to DIP. Since the DIP locus is exceptional among apomixis loci in that it lacks evidence for suppression of recombination, we investigated the occurrence of recombination in a larger region around DIP in more detail. We analyzed a random selection of 300 plants for S4, Mst78a and Mst53b in addition to S8 and S10, and compared the distance between the Mst loci with those between alleles at non-DIP homolog's. Allele sequence divergence between the DIP chromosome and non-DIP homolog's was measured at six marker regions at different distances from DIP. For this, we sequenced cloned PCR-products originating from the sexual parent, a diplosporous offspring plant, and an unrelated apomictic dandelion. Our results resolved a more detailed map of DIP and confirmed that suppression of recombination and allele sequence divergence play a minor role in the DIP-chromosomal region in T. officinale. We found an unexpected bias towards diplosporous reproducing recombinants, which we explained by postulating a duplicated DIP-locus rather than a single gene.

\section{Results}

\section{Fine-mapping of DIPLOSPOROUS}

In this study, we fine-mapped diplospory in Taraxacum by extending the population of 73 plants used for initial mapping [38] to a total of 2227 offspring plants analyzed here. This population originated from a cross between a sexual maternal plant and a diplosporous, but non-parthenogenetic, paternal plant. The dominant SCARs S8 and S10 were used to screen for recombinants. Presence of the diagnostic PCR products of both, S8 and S10, indicated the presence of the DIP-chromosomal region, whereas the presence of one of the two markers only indicated a recombination within this region (Figure 1). The results showed 1068 plants (47.9\%; Table 1) positive for S8 and S10, 1135 plants (51.0\%) negative for both markers, and 24 plants (1.1\%) recombinant. From the recombinants, nine were positive for S8 and negative for S10 and 15 showed the opposite score. This made the total frequencies of S8 and S10 fragments $48,4 \%$ and $48,6 \%$, respectively, both lacking a significant deviation from the expected 1:1 segregation rate $\left(S 8+/ S 8-=1077: 1150, \mathrm{Chi}^{2}=2.39, \mathrm{p}>0.1 ; S 10\right.$ $+/$ S10- $\left.=1083: 1144, \mathrm{Chi}^{2}=1.67, \mathrm{p}>0.1\right)$. Our results confirmed the dominant inheritance of $\mathrm{S} 8+/ \mathrm{S} 10+$, respectively the $D I P$-chromosomal region, in a much larger population than screened before. In addition, they reduced the distance between S8 and S10 from $2.7 \mathrm{cM}$ in the previous study to $1.1 \mathrm{cM}$ found here, and indicated that S10 was more closely linked to DIP than S8.
The 24 recombinants between S8 and S10 were phenotyped for their mode of reproduction via crosses with sexual diploid pollen donors followed by analyzing the offspring for their ploidy levels. A total of 20 offspring plants, ten of each of two crosses, were analyzed per recombinant, and chromosome numbers were deduced from flow cytometric analysis (see Methods for exact measurements and definitions). The results showed 20 recombinants (83\%; Table 1) to be diplosporous and four being meiotic, clearly deviating from the expected 1:1 segregation rate $\left(D I P: M E I=20: 4, \mathrm{Chi}^{2}=10.67,0.01\right.$ $>\mathrm{p}>0.001)$. Fourteen of the diplosporous recombinants showed strong penetrance of diplospory, that is, $\geq$ of the offspring plants (18 to 20 out of the 20 measured) showed DNA ratios $\geq 1.79$ as compared to a diploid ( tetraploid). The other six showed reduced penetrance of diplospory varying from $80 \%(\mathrm{n}=2)$, to $75,70,63$ and $50 \%$. This was supported by two to four additional crosses for each of these recombinant plants (data not shown).

A random set of 61 plants of the mapping population were phenotyped via crosses in an earlier study [44]. This showed 27 diplosporous and 34 meiotic plants, supporting a $1: 1$ segregation rate $(D I P: M E I=27: 34$, $\mathrm{Chi}^{2}=0.80, \mathrm{p}>0.1$ ), and a high penetrance of diplospory in the diplosporous individuals: $98.5 \%$ of the offspring showed the tetraploid chromosome set. The DIPlinked AFLPs co-segregated with the diplosporous phenotype [38]. Accordingly, we deduced the diplosporous phenotype and a high penetrance of diplospory from the $\mathrm{S} 8+/ \mathrm{S} 10+$ genotype in the remainder of the population. The final result showed 1088 diplosporous (1068 S8 $+/ \mathrm{S} 10+$ plants plus 20 diplosporous recombinants = 48.9\%; Table 1) and 1139 meiotic plants (51,1\%), confirming the expected 1:1 segregation rate $(D I P: M E I=$ 1088:1139, $\left.\mathrm{Chi}^{2}=1.17, \mathrm{p}>0.1\right)$. In summary, our results showed a strong bias towards diplosporous individuals among the recombinants, whereas they confirmed a 1:1 segregation rate of diplospory versus meiotic reproduction in the entire mapping population. One third of the diplosporous recombinants showed incomplete penetrance of diplospory.

Further fine-mapping of DIP was based on the 24 recombinants and the AFLPs known to be closely linked to DIP [38]. One of the two most closely linked clusters of three AFLPs showed resolution: S7 was closer to DIP than S8 and the third marker of this group. The other cluster remained unresolved, indicating that the markers of this group are as far or farther from DIP than S10 on the genetic map. The markers at larger distances from DIP co-segregated with the more closely linked AFLPs as expected, confirming the nature of the recombinants as well as the results from the previous study. Five recombinants showed a recombination between DIP and 


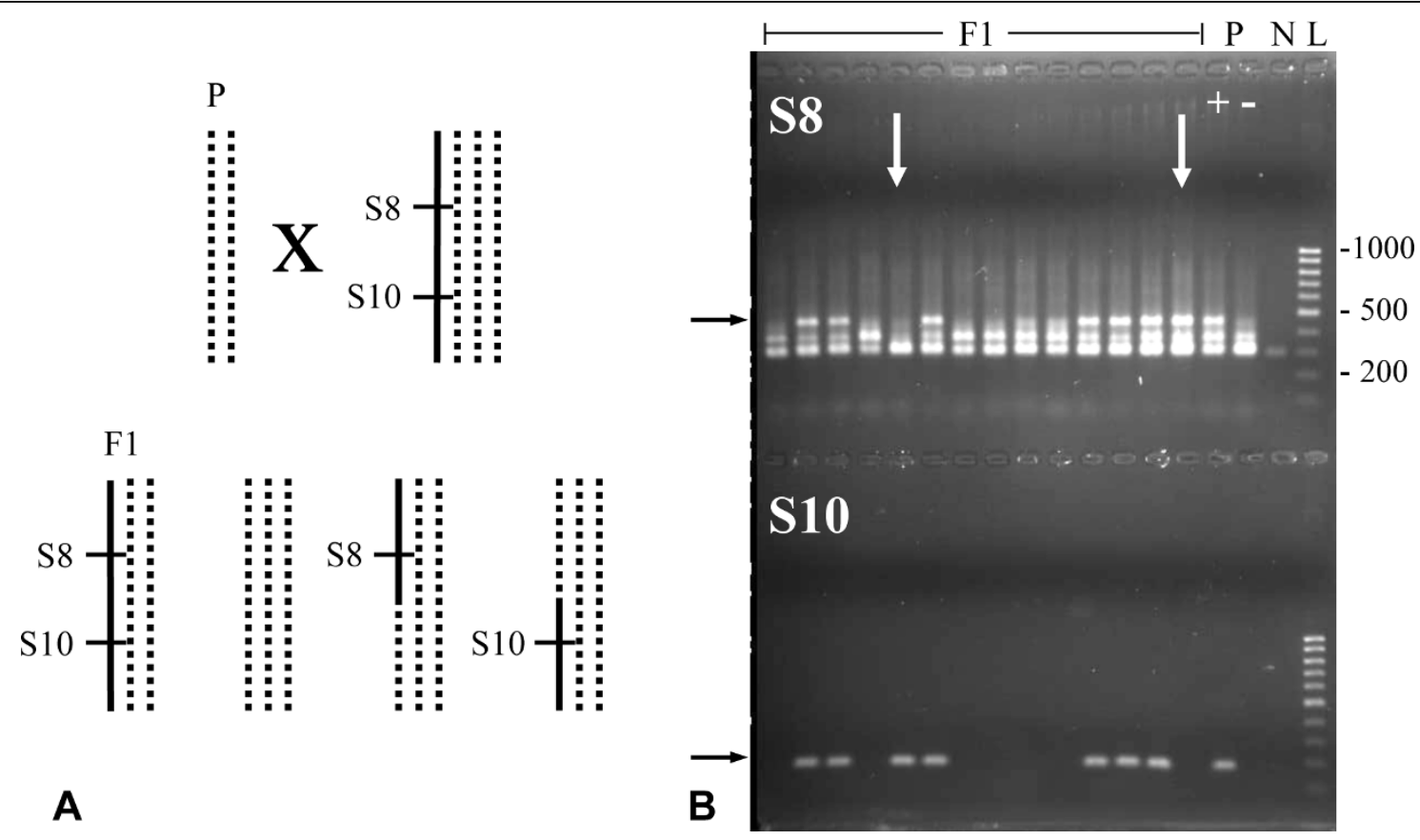

Figure 1 Genotypes of parents (P) and offspring (F1) of the cross used to map diplospory in T. officinale. (A) Crossing scheme showing the sexual diploid maternal plant $\mathbf{S 2 . 1 2 5}$ (dd, dotted lines), the diplosporous tetraploid pollen donor PAX (Dddd, with $D=$ solid line), and their possible triploid offspring (Ddd, ddd, and D/d-dd recombinants). S8 and S10 span DIP in $2.7 \mathrm{CM}$ [38], and the S8+/S10+ genotypes represent the D-alleles. (B) Agarose gel showing amplicons of S8 (upper half) and S10 (lower half) of 14 F1 and the two parent plants, with the diagnostic products (black arrows) and recombinant plants (white arrows) indicated. Plants with both markers present were interpreted as being diplosporous and those with both markers absent as being meiotic. $\mathrm{N}=$ negative control and $\mathrm{L}=100$ bp ladder.

S10 and 19 between DIP and S8 (Table 2), supporting the above made suggestion that $\mathrm{S} 10$ is closer to $D I P$ than S8. Our results reduced the map length of the DIP-locus from $1.1 \mathrm{cM}$ between S8 and $\mathrm{S} 10$ to $0.6 \mathrm{cM}$ between S7 and S10. They showed that S7 was most closely linked to DIP at one flank, at $0.4 \mathrm{cM}$, and S10 probably at the other flank, at $0.2 \mathrm{cM}$.

Table 1 Genotypes and phenotypes of the 2227 plants used to map diplospory

\begin{tabular}{|c|c|c|c|}
\hline Genotype or Phenotype & \# of Plants & & Frequency $(\%)^{a}$ \\
\hline $\mathrm{S} 8+/ \mathrm{S} 10+$ & 1068 & & 47.9 \\
\hline S8+/S10- & 9 & $\operatorname{Recs}^{b}$ & 1.1 \\
\hline S8-/S10+ & 15 & & \\
\hline S8-/S10- & 1135 & & 51.0 \\
\hline$\overline{S 8+}$ & 1077 & & $48.4^{n s}$ \\
\hline S10+ & 1083 & & $48.6^{n s}$ \\
\hline$\overline{D I P}$ & 1088 & & $48.9^{n s}$ \\
\hline MEl & 1139 & & $51.1^{n s}$ \\
\hline$\overline{D I P} \operatorname{Recs}^{\mathrm{b}}$ & 20 & & $83.3^{* *}$ \\
\hline MEI Recs & 4 & & $16.7^{* *}$ \\
\hline
\end{tabular}

${ }^{a}$ With deviations from a 1:1 segregation rate indicated:

$n s=p>0.1 ;{ }^{* *}=p<0.01$

${ }^{\mathrm{b}}$ Recs $=$ Recombinants
The marker distribution over a larger DIP-chromosomal region was investigated on the basis of 300 individuals, including the 73 plants of the initial mapping population and a random set of 227 plants chosen from the extended population used here. These plants were screened for the PCR-markers S4, Mst78a and Mst53b in addition to S8 and S10. Results are summarized in Table 2 . The distance between the most widely separated markers, S4 and Mst53b, was $7.3 \pm 3.0 \mathrm{cM}$, which was comparable to $9.6 \mathrm{cM}$ found previously [38]. The distance between Mst78a and Mst53b was $2.3 \pm 1.7 \mathrm{cM}$, which was in a better agreement with the 5-10 cM found at non-DIP homolog's in Taraxacum in earlier studies [42-44] than their close linkage in our initial $D I P$-map [38]. It also non-significantly deviated from the $6.3 \mathrm{cM}$ between these Mst alleles at the non-DIP homolog's in the diploid sexual parent S2.125 in this study $\left(\mathrm{Chi}^{2}=1.86, \mathrm{p}>0.1\right)$. The distance between the Mst78 and Mst53 alleles at non-DIP homolog's in the tetraploid diplosporous parent PAX varied from $4.7 \mathrm{cM}$ to 10.3 and $12.7 \mathrm{cM}$, the latter two significantly deviating from the $2.3 \mathrm{cM}$ found at the DIP-homolog. Excluding the results from one of the five flower heads, because it showed a strong bias towards recombination's between two particular allele combinations, reduced the 


\begin{tabular}{|c|c|c|c|c|c|c|}
\hline \multirow[t]{2}{*}{ Map } & \multicolumn{2}{|l|}{$A$} & \multicolumn{2}{|l|}{ B } & \multicolumn{2}{|l|}{$\mathrm{C}$} \\
\hline & $\#$ & $\begin{array}{l}\text { length } \\
\text { (cM) }\end{array}$ & $\#$ & $\begin{array}{l}\text { length } \\
\text { (cM) }\end{array}$ & $\#$ & $\begin{array}{l}\text { length } \\
\text { (cM) }\end{array}$ \\
\hline Population Size & 73 & & 300 & & 2227 & \\
\hline \multicolumn{7}{|l|}{ Recombinants } \\
\hline S4-Mst53b & 7 & $9.6 \pm 6.8^{\mathrm{a}}$ & 22 & $7.3 \pm 3.0$ & $\mathrm{nt}^{\mathrm{b}}$ & - \\
\hline $\mathrm{S} 4-\mathrm{S} 8$ & 2 & $2.7 \pm 3.7$ & 2 & $0.7 \pm 0.9$ & nt & - \\
\hline S10 - Mst78a & 3 & $4.1 \pm 4.6$ & 10 & $3.3 \pm 2.0$ & nt & - \\
\hline $\begin{array}{l}\text { Mst78a - } \\
\text { Mst53b }\end{array}$ & 0 & 0 & 7 & $2.3 \pm 1.7$ & $\mathrm{nt}$ & - \\
\hline $\mathrm{S} 8-\mathrm{S} 10$ & 2 & $2.7 \pm 3.7$ & 3 & $1.0 \pm 1.1$ & 24 & $1.1 \pm 0.4$ \\
\hline S8 - DIP & 1 & $1.4 \pm 2.7$ & $1-2$ & $\sim 0.5 \pm 0.8$ & 19 & $0.9 \pm 0.4$ \\
\hline$D I P-S 10$ & 1 & $1.4 \pm 2.7$ & $1-2$ & $\sim 0.5 \pm 0.8$ & 5 & $0.2 \pm 0.2$ \\
\hline $\mathrm{S} 7-\mathrm{S} 10$ & 2 & $2.7 \pm 3.7$ & $n t^{b}$ & - & 14 & $0.6 \pm 0.3$ \\
\hline $\mathrm{S} 7-\mathrm{DIP}$ & 1 & $1.4 \pm 2.7$ & $\mathrm{nt}$ & - & 9 & $0.4 \pm 0.3$ \\
\hline$D I P-S 10$ & 1 & $1.4 \pm 2.7$ & $1-2$ & $\sim 0.5 \pm 0.8$ & 5 & $0.2 \pm 0.2$ \\
\hline
\end{tabular}

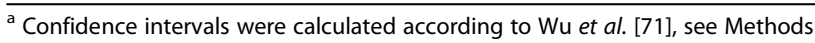
${ }^{\mathrm{b}} \mathrm{nt}=$ not tested

distance between the Mst alleles to $2.0 \mathrm{cM}$ at the DIPchromosome and 3.7, 4.3 and $6.7 \mathrm{cM}$ at the non-DIP homolog's in PAX, lacking a significant deviation between the extremes $\left(\mathrm{Chi}^{2}=2.54, \mathrm{p}>0.1\right)$. In summary, our results confirmed the occurrence of recombination in the $D I P$-chromosomal region and lacked strong support for the existence of a 'cold spot', a region in which recombination is suppressed, at the Mst78 and Mst53 loci located at $\sim 3.5 \mathrm{cM}$ from DIP at one flank.

An overview of the mapping results is given in Figure 2. Map A is redrawn from our previous study [38] with some minor updates [[16], this study]. It has a total length of $18.6 \mathrm{cM}$ and shows a regular distribution of markers over the DIP-chromosomal region. DIP is located at one third of the map and markers co-segregating with DIP are lacking. Map B zooms in to a region of $\sim 8 \mathrm{cM}$ around $D I P$, based on 300 plants and five PCR markers. It confirms the occurrence of recombination in this region close to DIP and lacks strong evidence for local suppression of recombination at the Mst78-Mst53 region. Map $C$ shows the fine-map of DIP based on the 24 recombinants between S8 and S10 out of the 2227 plants analyzed and the six most closely linked AFLPs. It shows partial resolution of the AFLP cluster at one flank of DIP and no further resolution of the AFLP cluster at the other flank of DIP. The length of the smallest DIP-chromosomal region was reduced to $0.6 \mathrm{cM}$, and the markers most closely linked to DIP are S7 and the cluster with $\mathrm{S} 10$ at $0.4 \mathrm{cM}$ and $0.2 \mathrm{cM}$, respectively.

\section{Segregation distortion and incomplete penetrance of diplospory}

In order to investigate whether the biased distribution towards diplosporous reproduction in the recombinants and the occurrence of a reduced penetrance of diplospory in some of them was correlated to a particular DIP-chromosomal region, the 24 recombinants were classified according to their place of recombination and DIP-flank involved. A total of six recombination types were possible, those between S8 and S7 (types I and VI; Figure 3), S7 and DIP (types II and V), and DIP and S10 (types III and IV), and their frequencies and accompanying average penetrance of diplospory were indicated (Figure 3). The scheme visualized the segregation distortion towards diplosporous recombinants (20 out of 24 , see above) and showed that this was irrespective of the DIP-flank involved (types I versus VI, II versus V, and III versus IV). Incomplete penetrance of diplospory was associated with a region close to DIP at one flank (type III). Zooming in to the region between S7 and S10 showed an enforcement of the skewed distribution to 13 diplosporous versus one meiotic recombinant. Further zooming in to a region that covers $\sim 0.2 \mathrm{cM}$ at each side of DIP suggested that all recombinants are diplosporous here (Figure 3, boxed). Our results indicated that meiotic recombinants with a $D I P$-flank approaching $D I P$ were either not formed or behaved diplosporously (type IV became included in type II and type V in type III, see discussion). They suggested that a reduced penetrance of diplospory is associated to a region close to $D I P$, particularly at the flank towards S10.

To further investigate the association of a reduced penetrance of diplospory to (a) particular chromosome region(s), the frequencies of offspring per chromosome number classes were depicted in a graph (Figure 4). This visualized the highest frequencies of reduced offspring in recombinants of type III (Figure 4A, black bars) and showed that these reductions were relatively severe, that is, they resulted in offspring with $\leq 24$ chromosomes, indicating the formation of haploid to diploid eggs. Type III included the three plants with lowest penetrance of diplospory (50-70\%), whereas the other three recombinants with reduced penetrance were of Types I and II (Figure 4A, grey bars). These plants showed less reduced penetrance of diplospory (75-80\%) and also milder reductions, that is, they resulted in offspring with 24-32 chromosomes, indicating the formation of di- to triploid eggs. Recombinants of type III were depicted individually to further visualize the pattern of reduced penetrance of diplospory (Figure 4B). This showed strong reductions of diplospory in plants R04, R08 and R11 (stripes and grey bars) and normal penetrance in R02 and R21 (white and black bars). The summary of results suggested that diplosporous reproduction in $T$. officinale is regulated by 


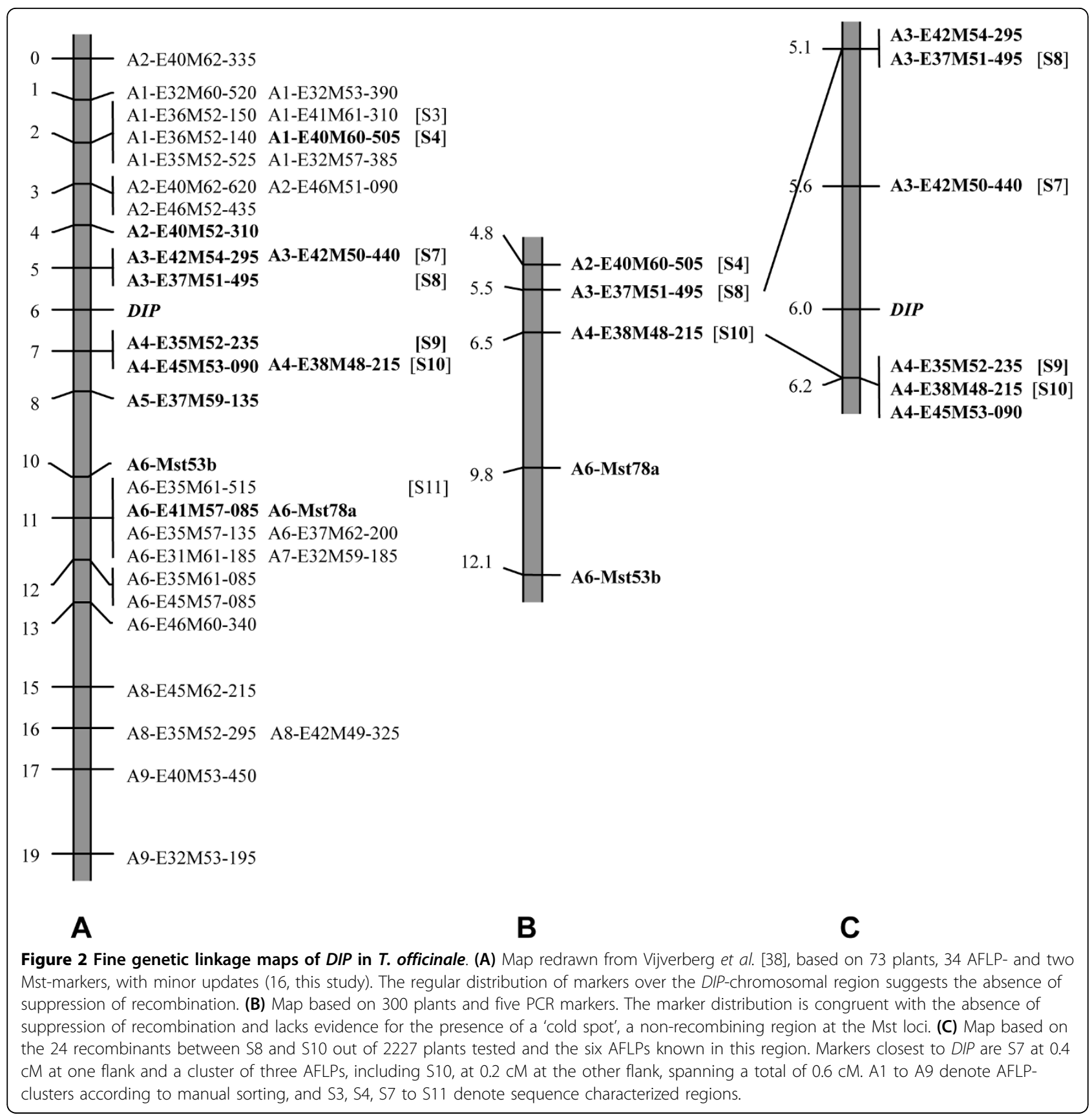

a more complex locus rather than a single DIP gene (see discussion), with the region towards S10 particularly being important for full penetrance of diplospory.

\section{Comparative analysis between DIP- and meiotic homolog's}

Sequence divergence between DIP- and non-DIP homolog's was investigated at six marker regions, representing both flanks and different distances to $D I P$, in order to further characterize the DIP-chromosomal region. For each region, PCR-products were obtained for the diploid sexual parent S2.125 (alleles $d 1$ and $d 2$ ), a triploid diplosporous offspring plant $\mathrm{F} 1.15(D, d 1$ and $d 3)$ and an unrelated natural apomictic $\mathrm{A} 68(D, d 4$ and $d 5)$ and sequences of cloned fragments analyzed. The results showed (many) more sequences than the expected two or three alleles per individual, indicating repetitivety of the DIP-linked sequences. As a result, $d$ alleles could not always be identified unambiguously and two of the marker regions, $\mathrm{S} 3$ at $\sim 4 \mathrm{cM}$ at one flank of DIP and A4 from the cluster with S9 and S10 at $\geq 0.2 \mathrm{cM}$ at the other flank of DIP were excluded. For the remaining 


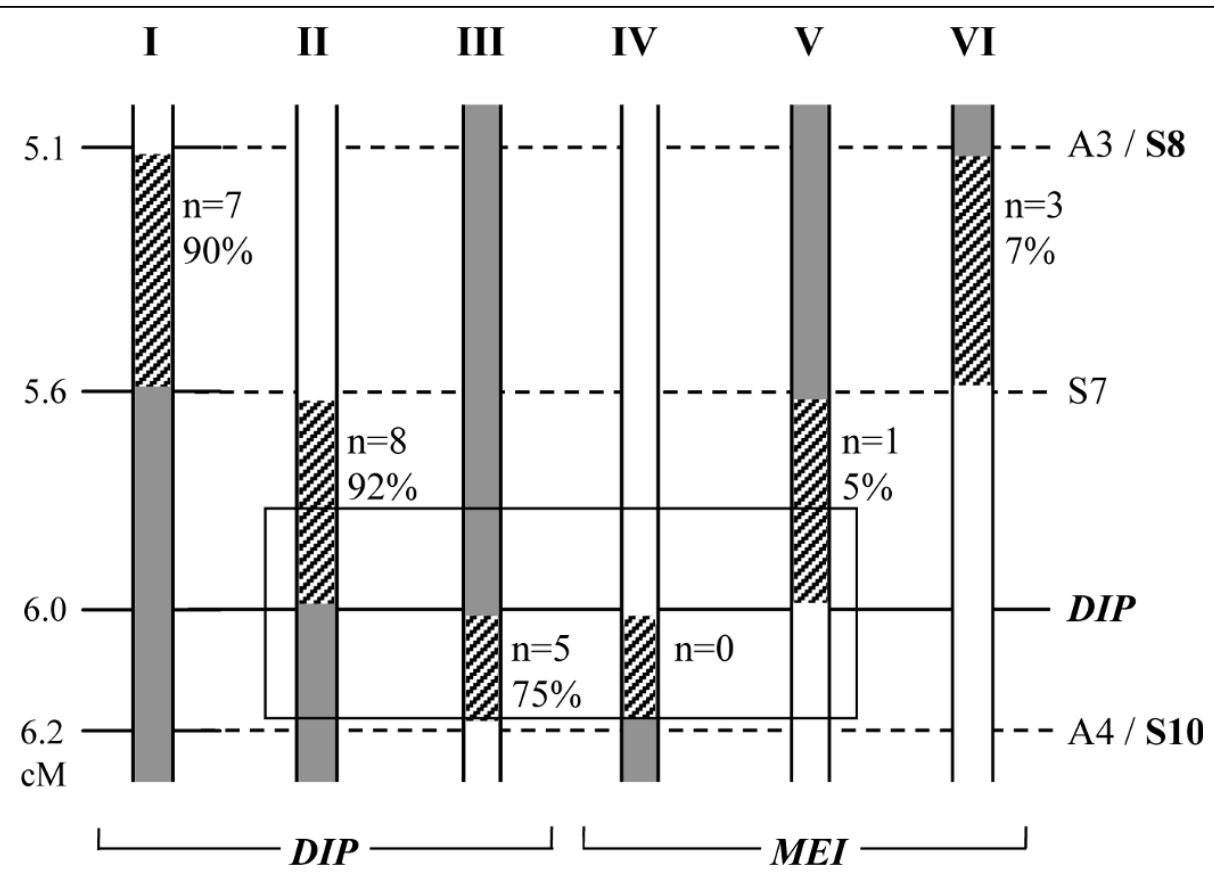

Figure 3 Schematic representation of recombination types (I to VI), their frequency ( $n$ ) and average penetrance of diplospory (\%). The types reflect the different locations of recombination (stripes) and DIP-flank involved (dark grey bar), with white bars representing the non-DIP chromosomal parts. The schedule visualizes the bias towards diplosporous recombinants (20 out of 24) and indicates that this is irrespective of the DIP-flank involved. The boxed region suggests an enforcement of this bias closer to DIP ( all are diplosporous). The reduced average penetrance of diplospory found in recombinants of type III suggests that the region between DIP and S10 contains essential elements for diplosporous reproduction. Marker distances follow the fine-map of Figure $2 \mathrm{C}$ and penetrance of diplospory are further visualized in Figure 4.

four regions, sequence comparison was restricted to $d 1$, $d 2$ and $D$-alleles only, after defining them as follows: $d 1$ and $d 2$ were the most frequent and least diverged marker sequences in $\mathrm{S} 2.125$ of which $d 1$ was also found in F1.15, and $D$ was the sequence identical to the known $D I P$-sequence and present in the diplosporous F1.15 as well as apomictic A68. Results are given in Table 3, with ' $p$ ' and ' $q$ ' representing extra sequences that occurred more than once in an individual and 'singles' indicating extra variants that were found only once. Sequence comparisons between DIP and non-DIP homolog's at S4 and S7 lacked significant differences (Table 3), indicating the absence of ASD at this flank at $\geq 0.4 \mathrm{cM}$ from DIP. Sequence comparisons at S10-flank where more difficult to interpret, because the large divergence between $d 1$ and $d 2$ could possibly be the result of the inclusion of (a) paralog('s). The overrepresentation of the $D$ allele in A68 may also point to sequence divergence at the primer sites of S10-flank at non-DIP homolog's. Since S10 is dominantly amplified (Figure 1), the presence of ASD at the S10 and possibly S10-flank region is indicated. For S11, the lack of $d 2$ alleles and close similarity of $d 1$ to $D$ may indicate that sequence divergence between $d 1$ and $d 2$ is absent. No preferential amplification of $D$ is indicated in F1.15, supporting a lack of ASD at this locus. In summary, our data lacks evidence for ASD at one flank > 0.4 cM from $D I P$ and at the other flank at larger distances from DIP. They suggest possible ASD at the S10 and S10-flank region at $\sim 0.2 \mathrm{cM}$ from $D I P$ at one flank.

\section{Discussion}

Recombination in the DIPLOSPOROUS-chromosomal region and the absence of overall allele sequence divergence make DIP a good candidate to isolate via a map-based cloning approach

Our data indicate that suppression of recombination plays a minor role in the DIPchromosomal region in T. officinale. This is supported by the equal distribution of markers over the DIP-map (Figure 2), the absence of markers co-segregating with diplospory, and the nonsignificantly deviating distances between the Mst78 and Mst53 alleles at DIP and non-DIP homolog's (Table 2 and Results). This result from the large segregating population confirms the conclusion of our initial mapping study [38], whereas possible local suppression of recombination at the Mst-region close to DIP is not supported. The occurrence of recombination in the DIP-chromosomal region is unique in comparison to other mapping studies of apomeiosis to date, that all showed strong suppression of recombination and in some cases hemizygosity at these loci (see Background) 


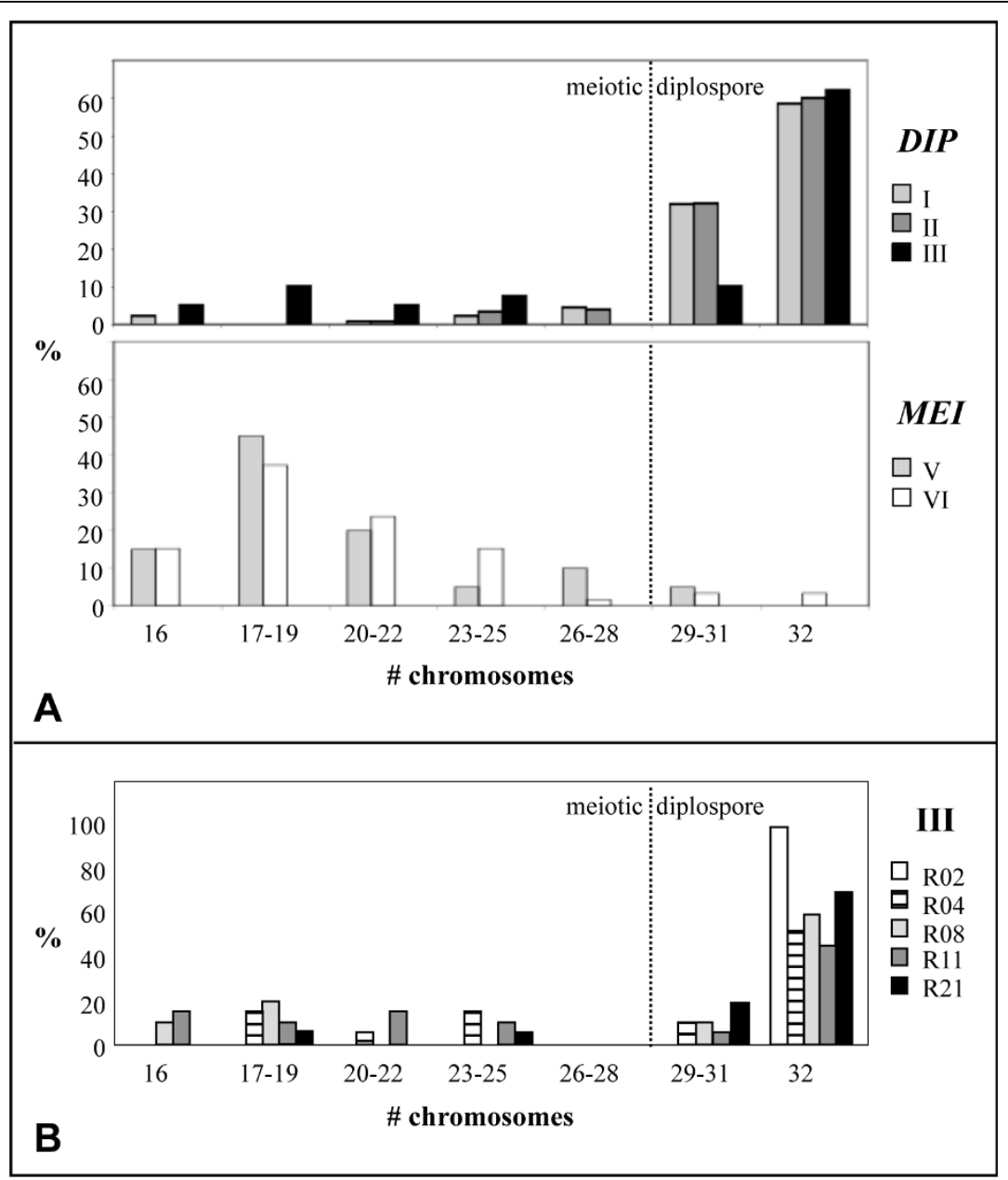

Figure 4 Graphical representation of penetrance of diplospory. The penetrance of diplospory is represented by the percentage of tetraploid plants among offspring of crosses between triploid recombinants and sexual diploid pollen donors. Chromosome numbers are derived from DNA contents as were determined by flow cytometry (see Methods). (A) Penetrance of diplospory averaged per recombination type (Figure 3), with diplosporous recombinants $(n=20)$ presented in the upper graph and meiotic ones $(n=4)$ in the lower graph. A minority of offspring plants, particularly of type III, showed incomplete penetrance of diplospory. (B) Penetrance of diplospory per plant of type III. Reduced penetrance were seen in plants R04 (stripes, 63\%), R08 (grey, 80\%), and R11 (dark grey, 50\%), whereas R02 (white, 100\%) and R21 (black, 90\%) are normal diplosporous.

[reviewed by [16,25]]. This has frustrated map-based cloning efforts of genes associated to apomixis in the species concerned. In one of the best examples among them, FISH experiments indicated that the aposporyspecific genomic region (ASGR) in Pennisetum squamulatum physically corresponds to $\sim 50 \mathrm{Mbp}$ or a quarter of a chromosome [54]. A recent mapping study in $P$. squamulatum, that made use of markers designed on long terminal repeat (LTR) sequences of ASGR-abundant transposon's, did also not resolve this region [55]. The occurrence of recombination around DIP in T. officinale offers a good opportunity to isolate an apomeiosis gene via further molecular marker searches based on the recombinants and BAC-walking from the markers most closely linked to DIP.
The present delimitation of DIP by S7 and S10 covers $0.6 \mathrm{cM}$. In comparison to tomato, which has a comparable genome size to $T$. officinale and for which $1 \mathrm{cM}$ was found to correspond to 0.3-0.4 Mbp [56], the DIPregion is estimated to cover a physical length of $\sim 200$ $300 \mathrm{~Kb}$. With an average BAC-size of the T. officinale BAC-library of $\sim 115 \mathrm{~Kb}$ [K Vijverberg et al. unpublished results] and supposing halfoverlapping BACs, this region could be closed by 4-6 BACs, making the isolation of DIP in Taraxacum feasible.

Our data show that overall ASD is lacking at the DIPchromosomal region. This is supported by the occurrence of recombination (see former paragraph) and by comparative sequence data at three of the DIP-linked marker regions analyzed, S4, S7 and S11 (Figure 2; Table 3). 
Table 3 Sequence divergence at marker regions between the DIP-allele and its non-DIP homolog's in T. officinale

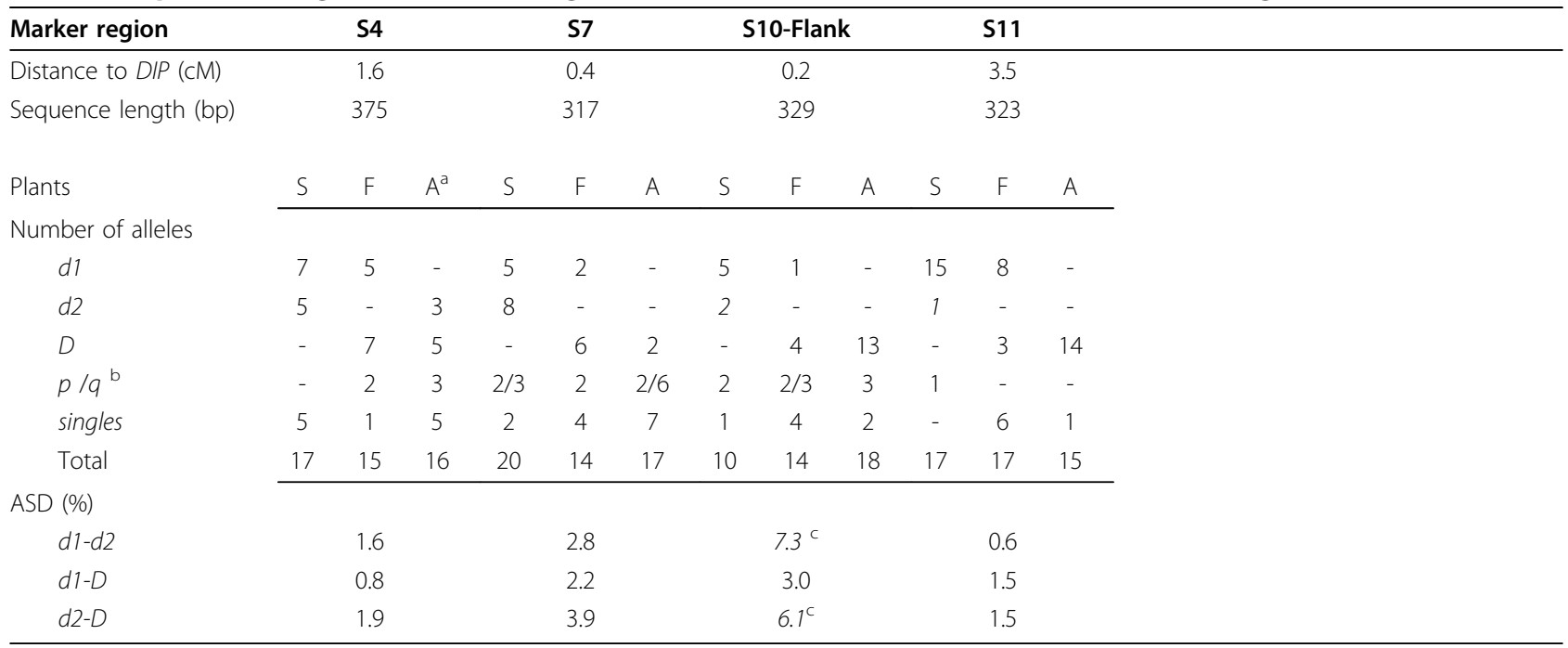

a $=$ S2.125; F = F1.15; A = A68

${ }^{\mathrm{b}} p$ and $q$ represent sequences that were found more than once in an individual and possibly include the $d 3$ allele in F1.15, $d 4$ and $d 5$ alleles in A68, or are paralogs; both $p$ and $q$ usually represent different sequences in the different individuals

' this high percentage of ASD is probably the result of a comparison between paralogs rather than homolog's

At the fourth marker region, S10-flank, and also at S10, preferential amplification of the DIP-homolog was indicated. This, and the clustering of S10 with two other AFLPs, may be signs of ASD and hemizygosity at this region close to DIP, although, the severity and locality of these signs are yet unknown. Increased ASD in regions associated with asexual reproduction can be expected as a result of the accumulation of mutations in the absence of 'homogenization' with homolog's via recombination [39-41]. The strong suppression of recombination and/or hemizygosity found at most loci associated with apomixis [e.g., $[29,54]]$ support this hypothesis. Also in sexuals, the occurrence of ASD in some regions of the genome has been indicated, e.g., haplotypic variability in maize was shown to strongly affect the frequency and distribution of recombination events [57]. Since Taraxacum is hermaphrodite, and apomixis concerns the female reproductive pathway only, recombination during pollen meiosis offers the possibility to retard ASD. By chance, overall this is expected to occur less frequently closer to DIP. Computer simulations of the depth of asexual reproduction history along a chromosome that carries a dominant single dose DIP-allele support this model [42]. It shows that the depth of asexual reproduction history accumulates with the number of generations also under sexual-asexual cycling conditions and is deepest at and close to DIP. This depth reduces at random generation times and positions across the flanks by incidental recombination events. When ASD becomes sufficiently pronounced, it will prevent for recombination also during pollen meiosis, which can lead to further increase of ASD. In addition to this gradual process, chromosome rearrangements may arise by chance and result in suppression of recombination immediately. In a heterozygous state, these mutations and rearrangements can accumulate without effect on apomictic seed production [45]. Our data are congruent with this model by suggesting that $\mathrm{S} 4$ and $\mathrm{S} 7$ at one flank of $D I P$ and $\mathrm{S} 11$ at the other flank of DIP have been homogenized by relatively recent recombination events, and the region around S10, located closer to DIP, may have a deeper history of asexual reproduction. Since recombination in the DIPregion between $\mathrm{S} 7$ and $\mathrm{S} 10$ is still possible (Figure 3), the possible ASD at the S10-region may be explained by a local rearrangement.

An earlier study in $T$. officinale suggested that a certain level of ASD is associated with DIP [58,42], by showing severe segregation distortion of the Mst78a and Mst53b alleles that are linked to DIP in haploid pollen grains, but not in diploid ones. A plausible explanation for this is that the DIP-allele is not transferred via haploid pollen due to pollen lethality as a result of linked deleterious mutations [45]. These mutations would be masked by (the) non-DIP allele(s) in a diploid or polyploid stage. A study in Tripsacum dactyloides also suggested that genes for apomixis might be linked to loci that are subjected to segregation distortion in haploid but not diploid gametes [32]. When apomixis genes cannot be transferred via haploid pollen, this could also explain the prevalence of apomixis in polyploids [42]. Our data indicate that overall ASD is absent at the DIP-locus, but we argue that recombination during pollen meiosis may have resulted in a mosaic pattern of different depths of asexual reproduction history along the $D I P$-chromosome (see former paragraph). In addition, local rearrangements may have accumulated in regions 
associated with asexual reproduction. The linkage of $D I P$ to a mutation load can then be explained by its confinement to (a) particular region(s) close to DIP. Alternatively, the non-transfer of $D I P$ via haploid pollen is associated to the DIP-allele itself. A pleiotropic recessive pollen lethal effect linked to apospory in Ranunculus auricomus was suggested by Nogler [1]. Possibly, a similar pleiotropic effect has evolved in the DIP-gene or is associated to asexual reproduction in general, however, this needs further investigations.

The occurrence of recombination and absence of overall ASD at the DIP-chromosomal region suggest that diplospory and apomixis are relatively recent in $T$. officinale. The clustering of markers found at the PAR-locus [PJ Van Dijk et al. unpublished results], however, seems to be in contrast to this conclusion. The evolution of either DIP or $P A R$ alone is unlikely, since they lead to increased ploidy levels with each generation and haploid phenotypes, respectively, both expected to be evolutionary dead-ends in nature. The differences in marker clustering found at the DIP and PAR loci could possibly be explained by a different recombination history around these loci by chance [[42], see above], that has resulted in higher levels of ASD at the PAR- than DIP-locus. An alternative explanation is that the differences result from a difference in chromosome rearrangements at the $D I P$ - and $P A R$-locus as compared to their non-DIP and non-PAR homolog's. Also differences in mitotic crossover and gene conversion may have played a role at these loci. Particularly one of these latter processes could have been involved in the origin of a duplication/inverted repeat in the DIP-locus as is postulated in Figure 5 (discussed below). The results possibly indicate that apomixis in Taraxacum is older than suggested by the $D I P$-chromosomal region alone.

In summary, our results suggest that ASD is absent in a wider region around $D I P$, non-pronounced close to $D I P$, and possibly present locally at the S10- and possible other regions linked to DIP as well as at the PARlocus. This pattern of different levels of ASD linked to $D I P$ and PAR is congruent with the outcome of computer simulations of recombination during pollen meiosis in regions associated with asexual reproduction and, in addition, different histories of local rearrangements. A practical implication of the absence of clear ASD at the $D I P$-locus is that non-DIP homolog's in the BAC-library can be used in the BAC-walking process in order to isolate $D I P$.

\section{Segregation distortion towards diplosporous recombinants and incomplete penetrance of diplospory in some of them indicate a duplicated DIP-locus}

We found a five times over-representation of diplosporous plants among the 24 recombinants (Figure 3), whereas the 1:1 segregation rate of diplosporous versus meiotic reproduction was confirmed in a random set of 61 plants of the mapping population by phenotyping via crosses. This 1:1 segregation was also confirmed in the remainder of the 2227 plants analyzed, according to deduction from the S8/S10 genotypes (Table 1). The over-representation of diplosporous plants is thus indicated to be specific for plants with a recombination between S8 and S10. The bias towards diplosporous reproduction increases in recombinants with a $D I P$-flank closer to $D I P$ at both flanks towards the presumed single DIP gene (Figure 3). The apparent segregation distortion could find its origin in one of two crosses: (i) the parental cross: S2.125 $(2 x) \times$ PAX $(4 x, D$-allele) (Figure 1A) or (ii) the crosses used for phenotyping: F1 ( $3 x$, including $D / d$ recombinants) $\times$ sexual $(2 x)$. In the parental cross, possible explanations for this bias are a preferential transfer of $D I P$ to recombinant offspring plants or a decreased viability of meiotic recombinant F1's. In the crosses used for phenotyping, the bias is possibly explained by a shift towards diplosporous reproduction in recombinants with a $D I P$-flank approaching $D I P /$ the presence of a partial $D I P$-locus or by a misclassification of meiotic recombinants in diplosporous ones with reduced penetrance. In a tetraploid pollen donor, as is the case in the parental cross, normal bivalent formation and meiosis occur [e.g., [49]], making recombination events along the DIP-chromosome possible. In the diploid pollen as well as triploid offspring, a possible mutation load linked to $D I P$, as can be a result of long-term asexual reproduction, will be masked (see former paragraphs). If expressed, it will result in an under-representation of diplosporous individuals rather than an over-representation. If uncoupled, a mutation load could result in a reduced number of meiotic recombinants when it is selectively expressed in a sexual background. This does, however, not explain the reduced penetrance of DIP found in some of the recombinants and also not the effect found at both flanks: recombinants of both types IV and V are lacking (Figure 3). A modifier linked to DIP with a lethal effect in a sexual background, either in the pollen or early embryo stage, can be another possibility. Although uncoupling of the modifier may result in a lower expression of diplospory, also here, a single modifier does not explain the bias found at both flanks. The phenotyping of 61 random offspring plants also lacks signs of linkage of either favorable or deleterious mutations to diplospory. The segregation distortion towards diplosporous recombinants is, therefore, not strongly supported by a preferential transfer of diplospory or a decreased viability of meiotic offspring in the parental cross.

The segregation distortion of diplospory in the recombinants as well as the reduced penetrance of diplospory in some of them are better explained in the crosses used for phenotyping. Meiosis in these crosses occurs in 
triploid megasporocytes, making meiosis difficult and leading to high percentages of aneuploid gametes [e.g., [49]], whereas diplosporous non-reduction is unhindered. Although offspring plants resulting from aneuploid gametes survive (Figure 4), their number might be (slightly) reduced. The percentages of diplosporous offspring from plants with incomplete penetrance of diplospory may then, actually, be (slightly) lower. Accordingly, the six diplosporous recombinants with 50 to $85 \%$ penetrance of diplospory (Figures 3,4), out of the total of 20, represent a minimum. In Taraxacum, unreduced, balanced triploid sperm cells can arise from a disturbed triploid true meiosis [e.g., [49,59], own observation], although at low frequencies not exceeding the $10 \%$. Unreduced pollen formation is also known from other polyploidy species [60], and the few existing data for unreduced eggs suggest that the natural frequency of non-reduction is similar in megasporogenesis [[60] and references therein]. Occasional formation of triploid female gametes in meiotic triploid recombinants is, therefore, expected and indicated (Figure 4A, types $\mathrm{V}$ and VI). However, frequencies of $\geq 50 \%$ are too high to be explained without the action of diplospory.
Moreover, segregation distortion and incomplete penetrance of diplospory was found in the recombinants only and not in the other diplosporous offspring of the mapping population. Apomixis in Taraxacum is usually obligate or close to obligate [48-50], also indicating full penetrance of diplospory under natural conditions. Together, this argues against misclassification of meiotic individuals as diplosporous ones with reduced penetrance. Our data is better explained by the presence of a relatively large DIP-locus in Taraxacum that, in part, still results in diplosporous reproduction and, depending on the parts available, could result in incomplete penetrance of diplospory.

A hypothetical constitution of the DIP-locus that explains the segregation distortion as well as incomplete penetrance of diplospory in some of the recombinants is given in Figure 5. Since the over-representation of the diplosporous phenotype is irrespective of the DIP-flank involved, a locus with a minimum of two DIP-genes is postulated. The absence of plants of recombination types IV and V (Figure 3) is then explained by their misclassification in types II and III, respectively, that is, the recombined allele excludes the putative single DIP-gene 
(Figure 5, at $6.0 \mathrm{cM}$ ), but still induces diplosporous reproduction. The different penetrance of diplospory is best explained by assuming one or two enhancers or cis-regulatory elements (Figure 5). Another possibility is additional DIP-genes that may result in copy number variation in the different recombinants (not shown), however, the number of copies increases to explain our data. A certain distance between the genes, and the enhancers/regulators, is supposed in order to give rise to the different recombinants within the proposed length of $\geq 200-300 \mathrm{~Kb}$ between S7 and S10. Since incomplete penetrance of diplospory is most pronounced in three plants of type III (Figures 3,4), that have their recombination between DIP and S10, essential elements for obtaining diplospory are indicated to be located in this region. We postulate that a minimum requirement for obtaining full penetrance of diplospory is the presence of a complete DIP1 gene in combination with $E n 1$ (or cis-regulator1), whereas DIP1 or DIP2 alone or DIP2 in the presence of En2 only, result in reduced penetrance of diplospory.

Our results do not support a complex DIP-locus with different functional genes. Recently, the osd $1 /$ Atrec 8 / Atspo11-1 triple mutant in Arabidopsis was shown to produce a highly penetrant diplosporous phenotype: mitosis replaces meiosis (MiMe) [23]. In a similar way, the DIP-locus could consist of different functional genes. Genes with a combined action to produce a complex phenotype may be tightly linked as a result of coevolution, e.g., like the self incompatibility loci in Brassica $[61,62]$. The overrepresentation of the diplosporous plants among the recombinants, however, argues against such a complex locus with different functional genes, since recombination would destroy the diplosporous phenotype.

Incomplete penetrance of apomeiosis was also found in Erigeron annuus [63] and Poa pratensis [35] and suggested to be correlated to a genetic background. In the study in $E$. annuus, a diplosporous triploid plant was pollinated by a sexual diploid, indicating that the genetic variation originated from the paternal plant and was not the result of maternal and epigenetic effects. The penetrance of diplospory was $92 \%$ in the triploid maternal parent and varied from 41 to $89 \%$ in the tetraploid offspring plants. Noyes [63] suggested either the presence of (trans-acting) modifiers that act directly on the expression of diplospory, novel epistatic interactions, or a combination thereof. The Apospory initiator (Ait) gene in $P$. pratensis [35] is a dominant gene needed for apospory and leading, together with four other genes, and depending on their differences in expressivity and interactions, to apomictic reproduction. Ait is of the aposporous type, not modifying meiosis, but depending on the formation of aposporous initials. The penetrance of Ait was found to vary between 0 and $>80 \%$ : it was absent in the maternal plant, but $>50 \%$ penetrant in some of the offspring originating either from selfing or from crossing with a sexual. Since incomplete penetrance of diplospory was found in some of the recombinants only and not in the diplosporous offspring plants without a recombination between S8 and S10, a genetic background that modifies the expression of DIP is not supported. Our results are better explained by a direct effect of recombination in the DIP-locus, as proposed in Figure 5, and not as a result of trans-acting effects.

Duplicated genes have often been associated with apomixis, but in the context of polyploidy [2] and not in the form of a tandem or inverted repeat at a single chromosome. Possible exceptions to this are the recently found duplicated $B A B Y B O O M(B B M)$-like gene and some duplicated putative protein-coding regions in the ASGR [20]. Hypothesized functional roles of ploidy include epigenetic gene deregulation, e.g., through changes in methylation [64], and asynchronous gene expression [65]. Others proposed that these complexities evolved upon establishment of apomictic reproduction and may be secondary [25]. In Taraxacum [58,42] and Tripsacum [32], segregation distortion of apomixis genes in haploid but not diploid gametes also suggest a secondary role of polyploidy. Whether a segmental duplication, as is postulated here, has a functional relationship to those hypothesized for a polyploid genome is yet unknown, but it is interesting to observe a possible gene dosage effect related to apomeiotic reproduction. Eventually map-based cloning of the DIP-locus will reveal the real structure of this locus and will give more insight into its function.

Diplospory results in FDR gametes, which are considered to be superior to $2 n$-gametes from second division restitution (SDR) in that they transfer all or a most of the parental heterozygosity and epistasis intact to their progeny. SDR gametes, on the other hand, result in near-homozygous offspring, varying in their chromosome constitution and possible heterozygosity only at the ends of the chromosome. Although both types allow for raising the ploidy level in artificial crosses, FDR gametes allow for pyramiding mutations or valuable characteristics in the same genetic background. DIP as well as the other apomixis related apomeiosis genes are dominant alleles (reviewed by 16). Whether they represent a new function or act via the inactivation of normal functions, i.e., deregulate the sexual pathway, is since long be debated [e.g., $[3,64])$. A few genes that showed deregulation of female meiosis in sexual model species, resulting in FDR-gametes, have been reported to date. These include mob1 in Medicago sativa [66,67], dyad in Arabidopsis [21,22], and a non-reduction mutant ( $\mathrm{nrm}$ ) in maize [64]. In contrast to $D I P$, these genes are all 
recessive. The mutants give the desired phenotype, but possibly via a different (de-)regulation than found in apomicts. Together with the useful applications of a dominant FDR-gene in plant breeding, isolation of DIP and finding out its function is desired and highly intriguing.

\section{Conclusions}

In this study, we obtained interesting new insights into the structure of the locus for diplospory in Taraxacum. We fine-mapped DIP to a minimum of $0.6 \mathrm{cM}$, which is estimated to cover $\sim 200-300 \mathrm{~Kb}$, with the closest markers at $0.2 \mathrm{cM}$. We found a clear bias towards diplosporous recombinants in the DIP-region, irrespective of the DIP-flank involved. Some of the diplosporous recombinants showed incomplete penetrance of diplospory. We postulate a locus with a minimum of two DIPgenes, possibly including one or two enhancers or cisregulatory elements, (Figure 5), on the basis of these results. Our data confirm the minor role of suppression of recombination and allele sequence divergence in the DIP-chromosomal region. This makes DIP an excellent candidate to isolate via a chromosome-walking approach. Mapping and isolating a gene that encodes unreduced female gamete formation and/or an element of apomixis is since long being undertaken. The progress in Taraxacum reported here is an important step closer to this aim.

\section{Methods}

\section{Plant material}

The mapping population of $T$. officinale used for initial mapping of DIPLOSPOROUS [38] was extended to a total of 2227 individuals. The population originated from a tetraploid diplosporous, but non-parthenogenetic, pollen donor (PAX, $2 n=4 x=32$ ) and a sexual diploid maternal parent $(\mathrm{S} 2.125,2 n=2 x=16)$. PAX was the result of a cross between a non-apomictic, but diplosporous, triploid hybrid (H6-3 [51]) and a sexual diploid paternal plant. The tetraploid PAX produced sufficient diploid, reduced and recombined pollen to perform segregation studies on diplospory. The triploid offspring of PAX $\times$ S2.125 segregated c. 1:1 for diplosporous:meiotic reduction [44,38]. Seedlings were grown in the greenhouse and screened for recombination in the DIP-chromosomal region (described below). Recombinant plants were further raised in the greenhouse, phenotyped for diplospory, and analyzed for additional molecular markers in the DIP-chromosomal region.

\section{Screening for recombination in the DIP-chromosomal region}

DNAs were screened for recombination between two PCR-markers that were derived from the dominant
SCARs S8 and S10, spanning DIP in a total of $2.7 \mathrm{cM}$ [38]. Total DNAs were isolated from c. $5 \mathrm{mg}$ leaf tips via the 'RETCH method', using the CTAB procedure as described by Rogstad [68] and the modifications by Vijverberg et al. [38]. In this procedure, leaf tips were transferred to tubes (Costar $1.2 \mathrm{ml}$ tubes 4408 and caps 4418 ) that contained two steel balls (bicycle, $1 / 8$ " in 60 gross, Tiangin, China) and were placed in racks (Costar) on ice. After harvesting, $500 \mu \mathrm{l} \mathrm{CTAB-buffer} \mathrm{was} \mathrm{added}$ to each tube, and leafs were homogenized via shaking the racks $4 \times 1 \mathrm{~min}$. at $30 \mathrm{rps}$ in a $\mathrm{RETCH}$ shaker (MM200, Düsseldorf, Germany). At the end of the isolation procedure, DNAs were resuspended in $100 \mu \mathrm{l} \mathrm{T}{ }_{0.1} \mathrm{E}$ (10 mM Tris, $0.1 \mathrm{mM}$ EDTA, $\mathrm{pH}=8.0)$. Quality and quantity were checked by measuring the optical densities at 260 and $280 \mathrm{~nm}$ and analyzing $2 \mu \mathrm{l}$ on $1 \%$ agarose gels.

PCRs were performed in 96-wells plates, using 2-10 ng DNA, $2.5 \mu \mathrm{l} 10 \times$ PCRbuffer, $2.5 \mathrm{mM} \mathrm{MgCl} 2,0.5 \mathrm{mM}$ dNTPs, $1 \%$ polyvinylpyrrolidone (PVP-40, SigmaAldrich), $0.2 \mathrm{mM}$ of each primer, and 0.5 Units Taq DNA Polymerase (Expand High Fidelity PCR Systems, Roche Applied Science) in a total volume of $25 \mu$ l. One drop of mineral oil (Sigma-Aldrich) was used to overlay the reactions and PCRs were performed following $1 \times 2$ $\min .94^{\circ} \mathrm{C}, 38 \times\left(30 \mathrm{sec} .94^{\circ} \mathrm{C}, 30 \mathrm{sec}\right.$. annealing temperature, and $1 \mathrm{~min} .72^{\circ} \mathrm{C}$ ), $1 \times 5 \mathrm{~min} .72^{\circ} \mathrm{C}$, and a cooling down to $12^{\circ} \mathrm{C}$. Annealing temperatures of S8 and S10 primer pairs were $60^{\circ} \mathrm{C}$ and $57^{\circ} \mathrm{C}$, respectively, and primer sequences are described in Vijverberg et al. [38]. PCR products were analyzed on $1.5 \%$ agarose gels, with diagnostic bands showing lengths of $446 \mathrm{bp}$ and $168 \mathrm{bp}$ respectively (Figure 1 ).

\section{DIP-phenotyping}

Plants that showed recombination between S8 and S10 were phenotyped for diplosporous versus meiotic reduction via crosses, using sexual diploids as pollen donors [44]. The offspring was analyzed for their ploidy levels as deduced from flow cytometric analysis [59]. Diplosporous recombinants were expected to produce tetraploid offspring only, being the sum of a non-reduced triploid egg cell plus a haploid sperm cell [[51], type C plants]. They showed a DNA ratio $=2.0(=32$ chromosomes) as compared to a diploid reference species. Meiotic recombinants produced a range of di-, tri-, and up to a few tetraploid offspring, representing the result of an aberrant meiotic reduction, typical for a triploid, plus a haploid male genome [[51], type A plants]. This was indicated by DNA ratios $=1.0$ to 1.5 and some higher values. Ten offspring plants were analyzed of each of two crosses per recombinant. The penetrance of diplospory was calculated as the percentage of offspring out of the 20 plants measured that showed a DNA ratio 
$\geq 1.79$ ( $\geq 29$ chromosomes). This was after correction for the triploid recombinant parent by setting it's ratio to 1.5 (original ratios varied from 1.48 to 1.58 ). In natural triploids, the percentage of tetraploid offspring as a result of aberrant meiosis during microsporogenesis does not exceed 10\% [[44], own observations]. As a 'wide' threshold, recombinants that showed $<30 \%$ tetraploid offspring in addition to reduced offspring were regarded meiotic, whereas the remainder was defined as diplosporous with a complete or reduced penetrance.

\section{Genetic fine-mapping of DIP}

Plants that showed a recombination between S8 and S10 were analyzed for AFLPs known to be linked to DIP [[38], Figure 2A]. DNA was isolated from 0.5-0.6 g fresh leaves, using the CTAB protocol described by Rogstad [68], with the modifications suggested by Vijverberg et al. [38]. Isolated DNA was resuspended in $500 \mu \mathrm{l} \mathrm{T}{ }_{0.1} \mathrm{E}$, checked for content and purity as described above, and $200 \mathrm{ng}$ was used for AFLP analyses. AFLPs were generated according to the protocol of Keygene N.V. (Wageningen, The Netherlands) version 2.2 described by Vos et al. [69], including the modifications described earlier [38]. AFLPs tested included those of the unresolved marker groups most closely linked to DIP: A3-E42M50440 (= S7), A3-E37M51-495 (= S8), and A3-E42M54295 at one flank of DIP and A4-E35M52-235 (= S9), A4-E38M48-215 (= S10), and A4-E45M53-090 at the other flank of DIP. Marker names represent the AFLP groups (A3, A4), enzymes $(\mathrm{E}=E c o \mathrm{RI}, \mathrm{M}=M s e \mathrm{I})$, selective nucleotides in alphabetical order (31 = AAA, $32=$ AAC, 33 = AAG, etc.), and length of the fragments in base pairs. Seven markers at larger distances from DIP were analyzed as controls: A1-E40M60-505 $(=$ S4), A2E40M52-310, A2-E46M52- 435, A5-E37M59-135, A6E41M57-85 and the microsatellite alleles A6-Mst78a and A6-Mst53b. AFLPs were analyzed on a $L I-C O R I R^{2}$ automated sequencer (Biosciences, USA) and the relevant bands scored manually on the gel-output. Msts were analyzed on an $A L F$ DNA sequencer (Pharmacia) and scored manually.

\section{Investigating the marker distribution over a wider DIP-chromosomal region}

A subset of 300 individuals randomly chosen from the mapping population was, apart from S8 and S10, also screened for the polymorphic PCR markers S4, Mst78, and Mst53 that were located at larger distances from DIP, spanning a total of $9.6 \mathrm{cM}$. PCRs of S4 were performed as described for S8 and S10, using an annealing temperature of $53^{\circ} \mathrm{C}$. Subsequently, $5 \mu$ l products were digested overnight at $55^{\circ} \mathrm{C}$ with 1 unit BseGI (Fermentas GMBH, Germany) in $1 \times$ accompanying buffer in a reaction volume of $15 \mu$ l. Digests were analyzed on $1.5 \%$ agarose gels, showing undigested products of c. $430 \mathrm{bp}$ and digested ones of 270 and $160 \mathrm{bp}$. The DIP-associated S4 products lacked the BseGI recognition site, so that diplosporous individuals showed both, the undigested as well as digested products, whereas meiotic individuals showed digested products only. PCRs of Msts were performed as described by Falque et al. [43] and products were analyzed on a $L I$-COR $I R^{2}$ automated sequencer (Westburg, Leusden, The Netherlands). Since Mst-markers are co-dominant markers, with Mst78a and Mst53b being linked to DIP, they have the advantage to also resolve information about the meiotic homolog's involved.

\section{Data analysis and mapping}

AFLP-, Mst-, and phenotypic data was collected in a binary data base in Excel. Linkage analyses were performed on datasets: $A=$ the previous data set of 73 plants and 36 markers; $\mathrm{B}=$ the medium data set of 300 plants and five (to 36) markers; $\mathrm{C}=$ the entire data set of 2227 and two (to 36) markers. The data of each of the three data sets was sorted manually in such a way that recombination events were minimized. Linkage analyses were also performed by using Joinmap 3.0 [70], with either all data or only the recombinants included. For the Joinmap analysis, the $\mathrm{BC}$ population type was used, with the Kosambi mapping function and threshold values for LOD $>1.0$ and REC $<0.40$. For some sets of recombinants, LOD and REC threshold values were relaxed to $>0.3$ and $<0.45$, respectively. An updated map A was drawn on the basis of the Joinmap output [[16], this study], confirming our previous results [38]. Maps $B$ and $C$ were drawn on the basis of the manual sortings and manual calculations of recombination frequencies. Since Joinmap analyses for these two data sets were inaccurate due to many missing values for most individuals, this was used as a guidance only. Confidence intervals of the map distances were calculated according to Wu et al. [71], regarding the chance that the true recombination fraction $(r)$ is in the $95 \%$ interval under $\pm 1.96 \sqrt{ }(r[1-r] / n)$ conditions, with $n$ being the number of plants analyzed.

\section{Comparison of marker regions of DIP- versus non-DIP homolog's}

Sequences were obtained for marker regions S3, S4, S7, S10-flank, A4-flank and S11, covering 300-400 bp regions located at different distances from $D I P$ at both flanks (Figure 2A; Table 3). Individuals analyzed were the sexual diploid maternal parent S2.125, representing two meiotic homolog's ( $d 1$ and $d 2$ ), a diplosporous triploid offspring plant, F1.15, representing the DIP-chromosome, one meiotic homolog originating from S2.125, and a second meiotic homolog $(D, d 1$ and $d 3)$, and a 
natural triploid apomict, A68, containing the DIP-chromosome plus two meiotic homolog's $(D, d 4$ and $d 5)$. PCR products were obtained as described above and in Vijverberg et al. [38], using as S7 reverse primer: 5'-TACTCACTTCCCGATCAACTCAC-3', and as S10flank forward and reverse primers: 5'-TAGACTTGATGCTCCTTGACTTGG-3' and 5'-AAGGCTTCACATGAGGCAGTAAG-3', respectively. Products were cloned by using the pGem T Vector system II (Promega), according to the manuals description. Per individual, between 10 and 20 clones were sequenced per marker region (BaseClear, Leiden, The Netherlands), using an M13 primer. Sequences were compared by using the DNAstar software (Lasergene, London, UK) or CLC sequence viewer v6.2 (CLCbio, Aarhus, Denmark).

\section{Acknowledgements}

This research is part of the European Union funded project: "Natural apomixis as a novel tool in plant breeding (ApoTool)", contract number: QLG2-2000-00603 of the Quality of Life and Management of Living Resources section. The paper corresponds to publication number 4804 of the Netherlands Institute of Ecology (NIOO-KNAW).

\section{Author details}

${ }^{1}$ Netherlands Institute of Ecology (NIOO-KNAW), Centre for Terrestrial Ecology, NL 6666GA Heteren, The Netherlands. ${ }^{2}$ Current Address: Plant Genetics, IWWR, Radboud University Nijmegen, Heyendaalseweg 135, NL6525AJ Nijmegen, The Netherlands. ${ }^{3}$ Current Address: Keygene NV, NL6708PW Wageningen, The Netherlands.

\section{Authors' contributions}

$\mathrm{KV}$ participated in the design and coordination of the experiments, performed the genetic fine-mapping with AFLPs, comparative sequence analysis, and data and statistical analysis, and drafted and wrote the manuscript. SM carried out the RETCH DNA isolations and PCR-and Mstmarker screens. TB performed the DIP-phenotyping. PJvD conceived of the research, participated in the design and coordination of the experiments, and contributed to the discussion of the results and draft of the manuscript. All authors read and approved the final manuscript.

Received: 22 February 2010 Accepted: 26 July 2010

Published: 26 July 2010

\section{References}

1. Nogler hr GA: Gametophytic apomixis: Embryology of angiosperms SpringerVerlag, Berlin 1984

2. Bicknell RA, Koltunow AM: Understanding apomixis: Recent advances and remaining conundrums. Plant Cell 2004, 16(Suppl):S228-S245.

3. Grimanelli D, Leblanc O, Perotti E, Grossniklaus U: Developmental genetics of gametophytic apomixis. Trends Genet 2001, 17:597-604.

4. Juel $\mathrm{O}$ : Vergleichende untersuchungen über typische und parthenogenetische fortpflanzung bei der gattung Antennaria. K Sven Vetenskapsakad Handl 1900, 33:1-59.

5. Juel O: Die tetradenteilung bei Taraxacum und anderen Cichorieen. $K$ Sven Vetenskapsakad Handl 1906, 39:1-21.

6. Veilleux R: Diploid and polyploid gametes in crop plants: Mechanisms of formation and utilization in plant breeding. Plant Breed Rev 1985, 3:253-288

7. Spillane C, Steimer A, Grossniklaus U: Apomixis in agriculture: The quest for clonal seeds. Sex Plant Reprod 2001, 14:179-187.

8. Vielle-Calzada JP, Crane CF, Stelly DM: Apomixis: The asexual revolution. Science 1996, 274:1322-1323.

9. Miles JW: Apomixis for cultivar development in tropical forage grasses. Crop Sci 2007, 47(Suppl):S238-S249.
10. Kaushal P, Agrawal A, Malaviya DR, Siddiqui SA, Roy AK: Ploidy manipulation in guinea grass (Panicum maximum Jacq., Poaceae) utilizing a hybridization-supplemented apomixis-components partitioning approach (HAPA). Plant Breed 2009, 28:295-303.

11. Maynard-Smith J: The evolution of sex Cambridge Univ Press, Cambridge, UK 1978.

12. Barton $\mathrm{NH}$, Charlesworth B: Why sex and recombination? Science 1998, 281:1986-1990.

13. Otto SP, Lenormand T: Resolving the paradox of sex and recombination. Nat Rev Genet 2002, 3:252-261.

14. Hörandl E, Grossniklaus U, Van Dijk PJ, Sharbel TF: Apomixis: Evolution, mechanisms, and perspectives ARG Gantner Verlag, Rugell, Lichtenstein 2007.

15. Savidan Y: Transfer of apomixis through wide crosses. The flowering of apomixis: From mechanisms to genetic engineering Mexico, D.F.: CIMMYT, IRD, European commission DG VI (FAIR)Savidan Y, Carman JG, Dresselhaus T 2001, 153-167.

16. Vijverberg K, Van Dijk PJ: Genetic linkage mapping of apomixis loci. Apomixis: Evolution, mechanisms, and perspectives ARG Gantner Verlag, Rugell, LichtensteinHörandl E, Grossniklaus U, Van Dijk PJ, Sharbel TF 2007, 137-158.

17. Curtis MD, Grossniklaus U: Molecular control of autonomous embryo and endosperm development. Sex Plant Reprod 2008, 21:79-88.

18. Kaushal P, Malaviya DR, Roy AK, Shalini Pathak, Agrawal A, Ambica Khare, Siddiqui SA: Reproductive pathways of seed development in apomictic guinea grass (Panicum maximum Jacq.) reveal uncoupling of apomixis components. Euphytica 2008, 164:81-92

19. Schallau A, Arzenton F, Johnston AJ, Hähnel U, Koszegi D, Blattner FR, Altschmied L, Haberer G, Barcaccia G, Bäumlein H: Identification and genetic analysis of the APOSPORY locus in Hypericum perforatum L. Plant J 2010, 62:773-784

20. Conner JA, Goel S, Gunawan G, Cordonnier-Pratt M-M, Johnson VE, Liang C, W Haiming, Pratt LH, Mullet JE, DeBarry J, Yang L, Bennetzen JL, Klein PE, Ozias-Akins P: Sequence analysis of bacterial artificial chromosome clones from the apospory-specific genomic region of Pennisetum and Cenchrus. Plant Physiol 2008, 147:1396-1411.

21. Mercier R, Vezon D, Bullier E, Motamayor JC, Sellier A, Lefèvre F, Pelletier G, Horlow C: SWITCH1 (SWI1): A novel protein required for the establishment of sister chromatid cohesion and for bivalent formation at meiosis. Genes Dev 2001, 15:1859-71.

22. Ravi M, Marimuthu MP, Siddiqi I: Gamete formation without meiosis in Arabidopsis. Nature 2008, 451:1121-1124.

23. d'Erfurth I, Jolivet S, Froger N, Catrice O, Novatchkova M, Mercier R: Turning meiosis into mitosis. PLoS Biol 2009, 7:e1000124.

24. Olmedo-Monfil V, Durán-Figueroa N, Arteaga-Vázquez M Demesa-Arévalo $E$, Autran D, Grimanelli D, Slotkin RK, Martienssen RA, Vielle-Calzada J-P: Control of female gamete formation by a small RNA pathway in Arabidopsis. Nature 2010, 464:628-632.

25. Ozias-Akin P, Van Dijk PJ: Mendelian genetics of apomixis in plants. Annu Rev Genet 2007, 41:509-537.

26. Ebina M, Nakagawa H, Yamamoto T, Araya H, Tsuruta S, Takahara M, Nakajima K: Co-segregation of AFLP and RAPD markers to apospory in Guinea grass Panicum maximum (Jacq). Grass/ Sci 2005, 51:71-78.

27. Pupilli F, Labombarda P, Caceres ME, Quarín CL, Arcioni S: The chromosome segment related to apomixis in Paspalum simplex is homoeologous to the telomeric region of the long arm of rice chromosome 12. Mol Breed 2001, 8:53-61.

28. Labombarda P, Busti A, Caceres ME, Pupilli F, Arcioni S: An AFLP marker tightly linked to apomixis reveals hemizygosity in a portion of the apomixis-controlling locus in Paspalum simplex. Genome 2002, 45:513-519.

29. Ozias-Akins P, Roche D, Hanna WW: Tight clustering and hemizygosity of apomixis-linked molecular markers in Pennisetum squamulatum implies genetic control of apospory by a divergent locus that may have no allelic form in sexual genotypes. Proc Natl Acad Sci USA 1998, 95:5127-5132.

30. Jessup RW, Burson BL, Burow GB, Wang Y-W, Chang C, Li Z, Paterson AH, Hussey MA: Disomic inheritance, suppressed recombination, and allelic interactions govern apospory in buffelgrass as revealed by genome mapping. Crop Sci 2002, 42:1688-1694.

31. Goel S, Chen Z, Akiyama Y, Conner JA, Basu M, Gualtieri G, Hanna WW, Ozias-Akins P: Comparative physical mapping of the apospory-specific 
genomic region in two apomictic grasses Pennisetum squamulatum and Cenchrus ciliaris. Genetics 2006, 173:389-400.

32. Grimanelli D, Leblanc O, Espinosa E, Perotti E, González-de-León D, Savidan Y: Mapping diplosporous apomixis in tetraploid Tripsacum: One gene or several genes? Heredity 1998, 80:33-39.

33. Pessino SC, Evans C, Ortiz JPA, Armstead I, do Valle CB, Hayward MD: A genetic map of the apospory-region in Brachiaria hybrids: Identification of two markers closely associated with the trait. Hereditas 1998, 128:153-158.

34. Barcaccia G, Mazzucato A, Albertini E, Zethof J, Gerats A, Pezzotti M, Falcinelli M: Inheritance of parthenogenesis in Poa pratensis L: Auxin test and AFLP linkage analyses support monogenic control. Theor Appl Genet 1998, 97:74-82.

35. Matzk F, Prodanovic S, Bäumlein H, Schubert I: The inheritance of apomixis in Poa pratensis confirms a five locus model with differences in gene expressivity and penetrance. Plant Cell 2005, 17:13-24

36. Noyes RD, Rieseberg LH: Two independent loci control agamospermy (apomixis) in the triploid flowering plant Erigeron annuus. Genetics 2000 155:379-390

37. Catanach AS, Erasmuson SK, Podivinsky E, Jordan BR, Bicknell R: Deletion mapping of genetic regions associated with apomixis in Hieracium. Proc Natl Acad Sci USA 2006, 103:18650-18655.

38. Vijverberg K, Van Der Hulst RG, Lindhout P, Van Dijk PJ: A genetic linkage map of the diplosporous chromosomal region in Taraxacum officinale (common dandelion; Asteraceae). Theor Appl Genet 2004, 108:725-732.

39. Birky CW Jr: Heterozygosity, heteromorphy, and phylogenetic trees in asexual eukaryotes. Genetics 1996, 144:427-437.

40. Mark Welch DB, Mark Welch JL, Meselson M: Evidence for degenerate tetraploidy in Bdelloid rotifers. Proc Natl Acad Sci USA 2008, 105:5145-5149.

41. Mark Welch D, Meselson M: Evidence for the evolution of Bdelloid rotifers without sexual reproduction or genetic exchange. Science 2000, 288:1211-1215

42. Van Dijk PJ, De Jong H, Vijverberg K, Biere A: An apomixis-gene's view on dandelions. Lost sex: The evolutionary biology of parthenogenesis Springer, London, UKSchön I, Martens K, Van Dijk PJ 2009, 475-495.

43. Falque M, Keurentjes J, Bakx-Schotman JMT, Van Dijk PJ: Development and characterization of microsatellite markers in the sexual-apomictic complex Taraxacum officinale (dandelion). Theor Appl Genet 1998, 97:283-292.

44. Van Dijk PJ, Bakx-Schotman T: Formation of unreduced megaspores (diplospory) in apomictic dandelions (Taraxacum officinale, s.l.) is controlled by a sex-specific dominant locus. Genetics 2004, 166:483-492.

45. Richards AJ: Agamospermy. Plant breeding systems Chapman and Hall, London, UK 1997, 396-450.

46. Gustafsson A: Primary and secondary association in Taraxacum. Hereditas 1934, 20:1-31.

47. Gustafsson $\AA$ : Apomixis in higher plants III: Biotype and species formation. Lunds Univ Arrskr 1947, 43:183-370.

48. Malecka J: Embryological studies in Taraxacum palustre. Acta Biol Crac Ser Bot 1965, 8:223-235

49. Malecka J: Problems of the mode of reproduction in microspecies of Taraxacum section Palustria Dahlsted. Acta Biol Crac ser Bot 1973, 16:37-84.

50. Van Baarlen P, Van Dijk PJ, Hoekstra RF, De Jong JH: Meiotic recombination in sexual diploid and apomictic triploid dandelions Taraxacum officinale (L). Genome 2000, 43:827-835.

51. Van Dijk PJ, Tas ICQ, Falque M, Bakx-Schotman T: Crosses between sexual and apomictic dandelions (Taraxacum) II: The breakdown of apomixis. Heredity 1999, 83:715-721.

52. Sørensen T: Sexual chromosome-aberrants in triploid apomictic Taraxaca. Bot Tidskr 1958, 54:1-22.

53. Fürnkranz D: Cytogenetischen untersuchungen an Taraxacum im raume von Wien II: Hybriden zwischen T. officinale und T. pallustre. Oesterr Bot Zeitschift 1961, 108:408-415.

54. Akiyama Y, Hanna WW: High-resolution physical mapping reveals that the apospory-specific genomic region (ASGR) in Cenchrus ciliaris is located on a heterochromatic and hemizygous region of a single chromosome. Theor Appl Genet 2005, 111:1042-1051.

55. Huo H, Conner JA, Ozias-Akins P: Genetic mapping of the aposporyspecific genomic region in Pennisetum squamulatum using retrotransposon-based molecular markers. Theor Appl Genet 2009, 119:199-212.

56. Chang S-B, Anderson LK, Sherman JD, Royer SM, Stack SM: Predicting and testing physical locations of genetically mapped loci on tomato pachytene chromosome. Genetics 2007, 176:2131-2138.

57. He L, Dooner HK: Haplotype structure strongly affects recombination in a maize genetic interval polymorphic for Helitron and retrotransposon insertions. Proc Natl Acad Sci USA 2009, 106:8410-8416

58. Van Dijk PJ: Ecological and evolutionary opportunities of apomixis: Insights from Taraxacum and Chondrilla. Philos Trans R Soc Lond B Biol Sci 2003, 35:1113-1121.

59. Tas ICQ, Van Dijk PJ: Crosses between sexual and apomictic dandelions (Taraxacum) I: The inheritance of apomixis. Heredity 1999, 83:707-714.

60. Ramsey J, Schemske DW: Pathways, mechanisms, and rates of polyploidy formation in flowering plants. Annu Rev Ecol Syst 1998, 29:467-501.

61. Shiba $H$, Kenmochi M, Sugihara M, Iwano M, Kawasaki S, Suzuki G, Watanabe M, Isogai A, Takayama S: Genomic organization of the S-locus region of Brassica. Biosci Biotechnol Biochem 2003, 67:622-626.

62. Takuno S, Fujimoto R, Sugimura T, Sato K, Okamoto S, Zhang SL, Nishio T: Effects of recombination on hitchhiking diversity in the Brassica selfincompatibility locus complex. Genetics 2007, 177:949-958.

63. Noyes RD: Inheritance of apomeiosis (diplospory) in fleabanes (Erigeron, Asteraceae). Heredity 2005, 94:193-198.

64. Curtis MD, Grossniklaus U: Amphimixis and apomixis: Two sides of the same coin! Apomixis: Evolution, mechanisms, and perspectives ARG Gantner Verlag, Rugell, LichtensteinHörandl E, Grossniklaus U, Van Dijk PJ, Sharbel TF 2007, 37-62.

65. Carman JG: Do duplicate genes cause apomixis? Apomixis: Evolution, mechanisms, and perspectives ARG Gantner Verlag, Rugell, LichtensteinHörandl E, Grossniklaus U, Van Dijk PJ, Sharbel TF 2007, 63-92.

66. Barcaccia G, Albertini E, Rosellini D, Tavoletti S, Veronesi F: Inheritance and mapping of $2 n$-egg production in diploid alfalfa. Genome 2000, 43:528-537.

67. Citterio S, Albertini E, Varotto S, Feltrin E, Soattin M, Marconi G, Sgorbati S, Lucchin M, Barcaccia G: Alfalfa Mob1-like genes are expressed in reproductive organs during meiosis and gametogenesis. Plant Mol Biol 2005, 58:789-807.

68. Rogstad SH: Saturated NaCl-CTAB solution as a means of field preservation of leaves for DNA analyses. Taxon 1992, 41:701-708.

69. Vos P, Hogers R, Bleeker M, Reijans M, Vandelee T, Hornes M, Frijters A, Pot J, Peleman J, Kuiper M, Zabeau M: AFLP: A new technique for DNAfingerprinting. Nucleic Acids Res 1995, 23:4407-4414.

70. Van Ooijen JW, Voorrips RE: Joinmap ${ }^{\circledR}$ 3.0. Software for the calculation of genetic linkage maps. Plant Res Int (PRI) Wageningen, The Netherlands 2001.

71. Wu KK, Burnquist W, Sorrells ME, Tew TL, Moore PH, Tanksley SD: The detection and estimation of linkage in polyploids using single-dose restriction fragments. Theor Appl Genet 1992, 83:294-300.

doi:10.1186/1471-2229-10-154

Cite this article as: Vijverberg et al:: Genetic fine-mapping of

DIPLOSPOROUS in Taraxacum (dandelion; Asteraceae) indicates a duplicated DIP-gene. BMC Plant Biology 2010 10:154.

\section{Submit your next manuscript to BioMed Central and take full advantage of:}

- Convenient online submission

- Thorough peer review

- No space constraints or color figure charges

- Immediate publication on acceptance

- Inclusion in PubMed, CAS, Scopus and Google Scholar

- Research which is freely available for redistribution 